beginning to be recognized, and therefore that the present volume will be rapidly outdated by new discoveries. For the expert the symposium is obviously important, but pædiatricians responsible for the care of the newborn must also be aware of these diseases, for many present in the first few days of life with failure to thrive, acidosis and ketosis, and some are treatable by dietary restriction or co-enzyme therapy.

MARTIN BARRATT

\section{Price's Textbook of the Practice of Medicine}

edited by

Sir Ronald Bodley Scott KCVO MA DM FRCP

11 th edn ppxiv +1417 illustrated $£ 8$

London \&c.: Oxford University Press 1973

'Price's Textbook of the Practice of Medicine' has now been a standard work of reference for fifty years. The 11th edition sees the replacement of many distinguished contributors by equally distinguished physicians and medical scientists. This edition also sees a change of format in that such topics as genetics, immunology and cancer chemotherapy, for example, are dealt with in separate sections to avoid repetition in each section where they are relevant. Sections have a most helpful introduction summarizing the essential physiology and anatomy of the subject. The book is a remarkably comprehensive work of reference that need not fear its competitors, particularly at, for 1973 , the very reasonable cost of $£ 8$.

NIGEL COMPSTON

Rehabilitation of the Cancer Patient

15th Annual Clinical Conference on Cancer, 1970, University of Texas M D Anderson Hospital and Tumor Institute

pp $x+326$ illustrated $£ 9$

Chicago: Year Book Medical Publishers 1972

London: Lloyd-Luke

This book deals successfully with an aspect of management of malignant disease that has received far too little attention in the past. It represents the compilation of papers presented at the 15th Annual Clinical Conference on Cancer in Houston in 1970.

The sections deal variously with the physical and psychological aftermath of radical treatment of cancers of the head and neck region, limbs, breast and intestine. The calibre of individual chapters differs but generally a high standard is maintained throughout, with adequate illustration when appropriate.

The emphasis in the chapters dealing with head and neck and mammary cancer is on the psychological and social problems involved and the chapters on the breast are particularly sympathetic in this respect. The physical needs of patients with artificial abdominal stomata receive primary attention in the chapters on intestinal malignant disease and much useful advice is given.

There are two general sections on neurological problems of malignant disease and community aspects of rehabilitation respectively. The former section tends to drift away from the theme of rehabilitation, as for example in the chapter on neurological complications of cancer chemotherapy. The discussions relating to community responsibilities are most thoughtful and point the way to future developments in this field.

This is an excellent book which is well worth reading. Despite its elegance, however, the purchase price of $£ 9$ is excessive for a volume of this size.

IAN BURN

\section{Radiobiology}

by Jacob I Fabrikant MD PhD

pp xv $+421 £ 10$

Chicago: Year Book Medical Publishers 1972

London: Lloyd-Luke

This 400-page book is intended to be 'a limited view of radiobiology as a radiologist sees it'. Its plan is comprehensive, ranging from biophysics and cell biology through genetics and cell population kinetics to radionuclides and carcinogenesis, taking in immunobiology and radiotherapy on the way. A great deal of information is presented and the book may well be found useful by some readers. Little prior knowledge is assumed. Unfortunately the author's forte is not precise, accurate and economical description: there is a great deal of repetition and statements made are often inexact and sometimes misleading. It is to be regretted that the experimental points have been systematically omitted from nearly all the numerous figures illustrating quantitative relationships: the reader has no way of judging how well the perhaps idealized lines and curves represent the actual determinations.

R H MOLE

\section{Scientific Foundations of Neurology}

edited by Macdonald Critchley CBE MD

FRCP HOnFACP, James L O'Leary PhD MD

and Bryan Jennett MD FRCS

ppxiii +502 illustrated $£ 11$

London: William Heinemann Medical 1972

This book with Anglo-American editorship is intended to provide for clinicians the scientific background of their practice and investigations. Radiological investigations are excluded as being a subject in themselves, but otherwise the coverage is extensive. It includes sections on the motor system, epilepsy, the sensory system, higher nervous activity, the cerebral circulation, cerebrospinal fluid and intracranial pressure, diagnostic and therapeutic techniques as well as the physiology of nerve cells and glia. Other problems such as head injury and infections of thenervoussystem 